\title{
ENAMEL REMINERALIZATION POTENTIAL OF NOVEL DENTIFRICE WITH TETRACALCIUM PHOSPHATE/MONETITE POWDER COMPONENT
}

\author{
L. Medvecky, R. Stulajterova, M. Giretova, J. Mincik, M. Vojtko, J. Balko, \\ E. Petrovova
}

\begin{abstract}
The aim was to investigate the enamel health benefits of a novel toothpaste with active tetracalcium phosphate/monetite mixtures under de/remineralization cycling. The enamel de/remineralization cycling protocol was consisted of demineralization in $1 \%$ aqueous solution of citric acid at pH 3.6 with following treatment with toothpastes and soaking in remineralization storage solution. Effectiveness of toothpastes to promote remineralization was evaluated by surface microhardness measurements, enamel erosion depth, analysis of surface roughness and fluorescent optical method. The novel tetracalcium phosphate/monetite toothpaste had the same remineralization potential as commercial calcium silicate/phosphate toothpaste and significantly higher than control storage solution group $(p<0.05)$. Surface roughness was significantly lower after addition of fluorides to dentifrice $(p<0.05)$. The enamel erosion depth was significantly reduced by applying toothpastes as compared to negative control $(p<0.05)$ and did not differ from calcium silicate/phosphate toothpaste $(p>0.66)$. The results showed that dentifrice formulations containing active tetracalcium phosphate/monetite mixture with or without fluoride addition had excellent enamel remineralization potential under de/remineralization cycling and successfully promote remineralization of enamel with daily using in the form of toothpaste.
\end{abstract}

\section{Keywords: dentifrice, enamel, fluoride, remineralization, demineralization}

\section{INTRODUCTION}

Dentifrices represent widely used and effective tool for preventing the development of caries with ability to promote of enamel or dentin remineralization in dependence on their composition. The regular brushing of the teeth with a fluoride toothpaste can reduce the incidence of dental caries and fluoride ions can be delivered to the tooth surface, saliva and other tissues including plaque biofilm. In the case of the formation of fine $\mathrm{CaF}_{2}$ - like deposits on enamel surface these can act like fluoride reservoir for the protection of enamel hydroxyapatite or fluorohydroxyapatite to dissolution [1].

\footnotetext{
Lubomir Medvecky, Radoslava Stulajterova, Maria Giretova, Marek Vojtko, Jan Balko: Institute of Materials Research of SAS, Watsonova 47, 04001 Kosice, Slovakia

Jozef Mincik: Private Dental Practice,Vystavby 3, Kosice, Slovakia

Eva Petrovova: Institute of Anatomy, University of Veterinary Medicine and Pharmacy in Kosice, Komenskeho 73, Kosice, Slovakia
} 
The effectivity of toothpaste for promoting enamel health can be enhanced by the addition of calcium and phosphate compounds. The delivery of calcium and fluoride ions and the increase of plaque calcium concentration is one of possible ways to prevent demineralization by the rise in the cariostatic activity of toothpaste. The generally utilized phosphate and fluoride compounds in toothpaste composition represent sodium phosphate, calcium phosphates (brushite, amorphous calcium phosphates, casein phosphopeptidestabilized amorphous calcium phosphate (CPP-ACP), functionalized $\beta$-tricalcium phosphate (fTCP), nanohydroxyapatite, organophosphates), sodium monofluorphosphate, calcium glycerol phosphate, $\mathrm{NaF}$, amine fluoride and compounds of $\mathrm{Zn}, \mathrm{Sr}$ or Sn [2-6]. Another large group of highly effective toothpastes with anti-caries protection and remineralization potential is based on calcium silicates, calcium silicate/phosphates or bioglass (NovaMine ${ }^{\mathrm{TM}}$ ) and dual phase gel treatment with ability to improve the formation of nanohydroxyapatite coating on enamel or dentin surfaces [7-12]. It was revealed that the calcium silicate/phosphate deposits onto enamel surfaces supported formation of hydroxyapatite crystalline phases close to the enamel mineral hydroxyapatite [13]. It has been found the comparable remineralization effect (even in depth) of the calcium glycerolphosphate (CaGP)/fluoride toothpaste on enamel at lower content of fluorides (500 ppm $\mathrm{F}^{-}$) as in commercial $1100 \mathrm{ppm} \mathrm{F}^{-}$fluoride paste [14]. Strong enamel remineralization was found by applying of chewing gum with CPP-ACP component [15] and rinses containing $450 \mathrm{ppm} \mathrm{F}^{-}$or $225 \mathrm{ppm} \mathrm{F}^{-}$with a small amount of fTCP [16]. On the other hand no differences on reduction of artificial caries lesions were identified in in-situ study between CPP-ACPF, fTCP and fluoride pastes despite of a significant reduction in lesion area [17].

The commercial fluoride-free $\mathrm{ZnCO}_{3}$ /nanohydroxyapatite dentifrices had higher remineralizing effect than pure amine fluoride [18] but a low in vitro inhibition of caries demineralization was observed using the fluoride-free nanohydroxyapatite containing toothpastes [19]. Nanohydroxyapatite was used practically in the form of aqueous slurries directly applied on eroded enamels or admixed into acid drinks' [20-22]. The addition of nanohydroxyapatite especially to acid suspension caused supersaturation of saliva in relation to hydroxyapatite or fluorohydroxyapatite with following precipitation of fine calcium phosphate coating. On the other hand, the more active dentin desensitizer based on fluoride-free powder tetracalcium phosphate/monetite mixtures (TEETHMATE $^{\circledR}$ desensitizer) has been developed and it have to be applied on tooth surface in the form of slurries in phosphate solution. The advantage of above solution can be in higher activity of calcium phosphates because of the gradual hydrolysis and fast mutual interaction between components with the formation of calcium deficient hydroxyapatite. A lower effectivity of TEETHMATE $^{\circledR}$ (Kuraray Noritake Dental, Tokyo, Japan) desensitizer than Nanoseal ${ }^{\circledR}$ (Nippon Shika Yakuhin, Yamaguchi, Japan) desensitizer with fluoro-alumino-calcium silicate glass component was found as the result of the formation of a more stable fluoroapatite and silica on bovine dentin [23].

The aim of this paper was to develop simply applicable dentifrices with active tetracalcium phosphate/monetite mixture and to evaluate their enamel remineralization properties under de/remineralization cycling. The prepared toothpastes differenced by morphology or particle size of monetite phase from the TEETHMATE ${ }^{\circledR}$ powder component (microcrystalline tetracalcium phosphate/monetite mixture (micTTCPM)), which was used and compared with in situ prepared mixture containing the nanomonetite phase (TTCPM) with the same $\mathrm{Ca} / \mathrm{P}$ ratio as in commercial micTTCPM powder. In the next, the effect of fluoride addition (1450 $\mathrm{ppm} \mathrm{F}^{-}$as $\mathrm{NaF}$ ) to TTCPM dentifrice (TTCPMF) on the surface hardness recovery and microstructure of enamel surface was studied. Besides, the prepared 
toothpastes were compared with both the commercial dentifrice (SENSODYNE $^{\circledR}$, GlaxoSmithKline) containing calcium sodium phosphate/silicate and $1450 \mathrm{ppm} \mathrm{F}^{-}$as positive control and remineralization solution treated enamels as negative control.

\section{MATERIALS AND METHODS}

\section{Experimental dentifrices}

Experimental toothpastes were prepared using carboxymethylcellulose, glycerol, amorphous silica, sodium lauryl sulfate, sorbitol, xylitol, calcium phosphate mixture, NaF (in the case of fluoride pastes) and water. Tetracalcium phosphate/nanomonetite mixture was prepared according to Medvecky et al. (2015) [24]. The fluoride content in TTCPMF paste was 1450 ppm (NaF, analytical grade, Sigma-Aldrich) and $\mathrm{NaF}$ was before using refined by re-precipitation after dissolution in distilled water and following fast addition of ethanol (absolute, analytical grade, Reag,Pharm.Eur, Merck). The commercial microcrystalline tetracalcium phosphate/monetite powder mixture (micTTCPM) was used without any further treatment. SENSODYNE ${ }^{\circledR}$ dentifrice (CaPSi) was composed of calcium sodium phosphate/silicate, $1450 \mathrm{ppm} \mathrm{F}^{-}$as sodium monofluorphosphate, glycerin, PEG8, hydrated silica, sodium lauryl sulfate, titanium dioxide, carbomer, sodium saccharin, eugenol, limonene.

\section{Sample preparation}

The teeth used in experiment were extracted for orthodontic reasons and with the informed consent of patients (protocol No: 088/2005- PH/CEP). Crowns from freshly extracted human non-carious molars were sectioned from the roots horizontally and then vertically to obtain their buccal surfaces using a slow speed diamond disk attached to the micro-motor under water lubrication. The specimens were then embedded in self-cured two component epoxy resin $(3 \mathrm{M})$. The buccal/lingual surfaces were wet ground using 800, 1200,2400 and 4000-grit water proof silicon carbide paper (Struers) to obtain a smooth flat surface. The one halve of each flat enamel surface was coated with the water resistant nail varnish and was used as baseline for the evaluation of properties. Uncoated area of enamels (2x2 mm) was utilized as sample for treatment with dentifrices. Samples were soaked in physiological solution $(0.9 \% \mathrm{NaCl})$ until using.

\section{Surface microhardness analysis and surface roughness}

The surface microhardness was measured using microhardness tester (TUKON 1102, Wilson Hardness) with a Vickers indenter at $25 \mathrm{~g}$ load for $15 \mathrm{~s}$. Six indentations per test were performed on each specimen and the mean and standard deviation was taken. The surface hardness of the polished sound enamel $\left(\mathrm{VHM}_{\mathrm{s}}\right)$ was measured as baseline after removing of varnish. The final $\mathrm{VHM}_{\mathrm{f}}$ characterizes surface enamel microhardness after 10 de/remineralization cycles. The surface microhardness recovery $\triangle \mathrm{VMH}$ was calculated as $\left.\Delta \mathrm{VMH}=\left(\mathrm{VHM}_{\mathrm{s}}-\mathrm{VHM}_{\mathrm{f}}\right) / \mathrm{VHM}_{\mathrm{s}}\right) \times 100$.

The surface roughness $\left(\mathrm{S}_{\mathrm{a}}\right)$ of samples ( 5 samples of each group) was measured by the 3D optical profilometer (PLu Neox Sensofar, Spain) in a confocal mode with $200 \times$ objective (NA 0.95 , maximum slope $71^{\circ}$, vertical resolution $<1 \mathrm{~nm}$ ). The image analysis was done using the SensoMap standard software. The enamel erosion depth of samples (5 samples of each group) was calculated from profilometer line scans as the average distance $(\Delta \mathrm{h})$ between surface of polished sound enamel and enamel surfaces after 10 de/remineralization cycles (mean of three depth line profiles on each sample). 


\section{XRD phase analysis, SEM and optical fluorescent microscopy}

The phase composition of TTCPMF and micTTCPM pastes as prepared and after one year storage at $25{ }^{\circ} \mathrm{C}$ was analyzed by X-ray diffraction analysis (Philips X PertPro, using $\mathrm{Cu} \mathrm{K} \alpha$ radiation). The surface texture of enamels was observed by a scanning environmental electron microscopy (SEM EVO MA15 (Carl Zeiss, Germany) equipped with EDX/WDX system (Oxford Instruments, United Kingdom) after coating with gold (ion sputter, FINE COAT, Jeol JFC-1100; $1.2 \mathrm{kV}, 4 \mathrm{~mA}$ for $10 \mathrm{~min}$ ).

The fluorescent intensity ( $\mathrm{I}_{\text {fluor }}$ ) of enamels was observed by the inverted fluorescent optical microscope (Leica DM IL LED equipped with CCD camera) using blue filter (analysis of the difference in fluorescent intensities between sound and treated areas of enamel which allows to consider the degree of enamel demineralization $[25,26]$ at $100 \mathrm{x}$ magnification. The average fluorescent intensities from observed enamel rectangular areas with dimensions 400x400 $\mu \mathrm{m}$ were evaluated by the image analysis (ImageJ8 software). Note that none nonlinear filters were used during the images analysis.

\section{De/remineralization cycling}

The $1 \%$ solution of citric acid in distilled water at $\mathrm{pH} 3.6$ demineralization phase mimic a typical erosive challenge from acidic drinks (e.g. orange juice) with a similar titratable acidity [27,10]. Specimens were subjected to following de/remineralization protocol for cycling twice a day: firstly, the enamels ( $\mathrm{n}=10$ for each group) were subjected to an acid challenge ( $5 \mathrm{~min}, 1 \% \mathrm{w} / \mathrm{w}$ anhydrous citric acid in distilled water, $\mathrm{pH} 3.6$ at 37 ${ }^{\circ} \mathrm{C}$ ) and rinsed with distilled water; secondly, specimens were brushed with toothpaste slurry (2 min, 1:3 ratio of toothpaste:water) using common Oral B Pro_Health Precision Clean battery brusher (Braun) consequently rinsed with distilled water and dried with filter paper; thirstily, specimens were immersed to remineralization storage solution $(137.5 \mathrm{mM}$ $\mathrm{NaCl}, 3 \mathrm{mM} \mathrm{KCl}, 0.68 \mathrm{mM} \mathrm{CaCl}_{2}, 7.13 \mathrm{mM} \mathrm{K}_{2} \mathrm{HPO}_{4}, 0.5 \mathrm{mM} \mathrm{Na}_{2} \mathrm{SO}_{4}, 1.5 \mathrm{mM} \mathrm{MgCl} 2,4.2$ $\mathrm{mM} \mathrm{NaHCO} 3$ at $\mathrm{pH} 7,37{ }^{\circ} \mathrm{C}$ ) [28] with the concentration of magnesium, calcium and phosphate ions close to artificial saliva [29] for 12 hours. Summary was done 10 cycles before enamel specimens evaluation.

\section{Statistical analysis}

One-(testing null hypothesis) and two-way analysis of variance (ANOVA analysis, Statmost software) were used to examine and compare all measured specific properties of enamels $(\alpha<0.05)$. The Kolmogorov-Smirnov test showed that all data were normally distributed. The Student $t$ test (normal distribution) was used to calculate the 95\% confidence intervals for mean differences between groups.

\section{RESULTS}

The results of individual analysis are shown in Table 1 with statistical one- (null hypothesis) or two-way ANOVA analysis (comparison between groups) $(\alpha=0.05)$. The differences between average surface area roughnesses $\left(\Delta \mathrm{S}_{\mathrm{a}}\right)$ of sound and treated (CaPSi and TTCPMF) enamels were significantly lower than in negative control (storage solution) but no statistically significant differences in $\Delta \mathrm{S}_{\mathrm{a}}$ were found between fluoride-free groups and control. 
Tab.1. Comparison of selected parameters or properties of enamels measured after treatment with various toothpastes and cycling $-\Delta \mathrm{S}_{\mathrm{a}}$ (difference between surface area roughnesses of sound and treated enamel surfaces), $\Delta \mathrm{h}$ (erosion depth), $\Delta \mathrm{VMH}$ (surface microhardness recovery), $\Delta \mathrm{I}_{\text {fluor }}$ (differences between means of fluorescent intensities from untreated and treated area of enamels).

\begin{tabular}{|c|c|c|c|c|}
\hline & $\begin{array}{l}\Delta \mathrm{S}_{\mathrm{a}} \pm \mathrm{SD}[\mathrm{nm}] \\
\mathrm{n}=5\end{array}$ & $\begin{array}{l}\Delta \mathrm{h} \pm \mathrm{SD}[\mu \mathrm{m}] \\
\mathrm{n}=5\end{array}$ & $\begin{array}{l}\Delta \mathrm{VMH} \pm \mathrm{SD}[\%] \\
\mathrm{n}=10\end{array}$ & $\begin{array}{l}\Delta \mathrm{i}_{\text {flour }} \pm \mathrm{SD}^{*} \\
\mathrm{n}=10\end{array}$ \\
\hline TTCPM & $282 \pm 94$ & $6.4 \pm 1.8$ & $\begin{array}{l}18.2 \pm 8.2 \\
(p<0.001)^{*}\end{array}$ & $4.1 \pm 4.2$ \\
\hline TTCPMF & $183 \pm 12$ & $8.3 \pm 1.1$ & $\begin{array}{l}-9.8 \pm 24.8 \\
(\S, p>0.24)\end{array}$ & $5 \pm 4.8$ \\
\hline micTTCPM & $272 \pm 85$ & $6.5 \pm 2.0$ & $\begin{array}{l}-3.5 \pm 30.1 \\
(\S, p>0.72)\end{array}$ & $3.2 \pm 3.7$ \\
\hline CaPSi & $191 \pm 25$ & $6.8 \pm 0.8$ & $\begin{array}{l}0.57 \pm 23.4 \\
(\S, p>0.94)\end{array}$ & $6.0 \pm 4.1$ \\
\hline Storage solution & $380 \pm 46$ & $12.2 \pm 1.5$ & $\begin{array}{l}44.7 \pm 12.1 \\
(p<0.001)^{*}\end{array}$ & $22.2 \pm 6.8$ \\
\hline & \multicolumn{4}{|c|}{$95 \% \mathrm{Cl}$ of the difference (significate) } \\
\hline TTCPM vs TTCPMF & $\begin{array}{l}7.43,193.4 \\
(p<0.047)^{* *}\end{array}$ & $\begin{array}{l}-3.91,0.31 \\
(p>0.08)\end{array}$ & $\begin{array}{l}8.28,47.54 \\
(\mathrm{p}<0.033)^{* *}\end{array}$ & \\
\hline $\begin{array}{l}\text { TTCPM } \\
\text { vs storage solution }\end{array}$ & $\begin{array}{l}-200.5,11.3 \\
(p>0.07)\end{array}$ & $\begin{array}{l}-8.19,-3.49 \\
(\mathrm{p}<0.001)^{* *}\end{array}$ & $\begin{array}{l}-36.15,-15.58 \\
(\mathrm{p}<0.001)^{* *}\end{array}$ & \\
\hline $\begin{array}{l}\text { TTCPMF } \\
\text { vs micTTCPM }\end{array}$ & $\begin{array}{l}-157.3,-21.9 \\
(\mathrm{p}<0.05)^{* *}\end{array}$ & $\begin{array}{l}-0.66,3.94 \\
(p>0.12)\end{array}$ & $\begin{array}{l}-36.1,23.5 \\
(p>0.62)\end{array}$ & \\
\hline $\begin{array}{l}\text { TTCPMF } \\
\text { vs storage solution }\end{array}$ & $\begin{array}{l}-248.8,-141.2 \\
(\mathrm{p}<0.001)^{* *}\end{array}$ & $\begin{array}{l}-5.84,-2.24 \\
(\mathrm{p}<0.002)^{* *}\end{array}$ & $\begin{array}{l}-73.0,-34.56 \\
(p<0.001)^{* *}\end{array}$ & \\
\hline $\begin{array}{l}\text { micTTCPM } \\
\text { vs storage solution }\end{array}$ & $\begin{array}{l}-180.0,-20.8 \\
(p<0.037)^{* *}\end{array}$ & $\begin{array}{l}-8.20,-3.16 \\
(\mathrm{p}<0.002)^{* *}\end{array}$ & $\begin{array}{l}-71.18,-23.8 \\
(\mathrm{p}<0.001)^{* *}\end{array}$ & \\
\hline $\begin{array}{l}\text { CaPSi } \\
\text { vs storage solution }\end{array}$ & $\begin{array}{l}-238.3,-120.9 \\
(\mathrm{p}<0.001)^{* *}\end{array}$ & $\begin{array}{l}-7.11,-3.81 \\
(p<0.001)^{* *}\end{array}$ & $\begin{array}{l}-62.8,24.1 \\
(\mathrm{p}<0.001)^{* *}\end{array}$ & \\
\hline TTCPM vs CaPSi & $\begin{array}{l}-10.9,180.9 \\
(\mathrm{p}>0.07)\end{array}$ & $\begin{array}{l}-2.37,1.61 \\
(p>0.66)\end{array}$ & $\begin{array}{l}-1.71,36.88 \\
(\mathrm{p}<0.04)^{* *}\end{array}$ & \\
\hline TTCPMF vs CaPSi & $\begin{array}{l}-45.1,14.3 \\
(p>0.54) \\
\end{array}$ & $\begin{array}{l}0.13,2.71 \\
(\mathrm{p}<0.04)^{* *}\end{array}$ & $\begin{array}{l}-37.98,17.31 \\
(p>0.35)\end{array}$ & \\
\hline
\end{tabular}

$*$ all statistically different from null, $\mathrm{p}<0.05$

$\S$ not statistically different from null

$* *$ statistically different, $\mathrm{p}<0.05$

The addition of NaF to TTCPM (Fig.1a) caused the formation of smoother, a more compact and uniform surface microtexture (Fig.1b). Some microporosity (Fig.1d) with the presence of submicron $\mathrm{TiO}_{2}$ particles was identified by the point EDX analysis (Fig.2a) on CaPSi treated enamels. In the micTTCPM group (Fig.1c), the fraction of micropores in layer was much higher than in CaPSi group. A high roughness and the strong destruction of enamel structures after acid etching as well as soaking in storage solution only are clearly demonstrated in Figs. 1e. 

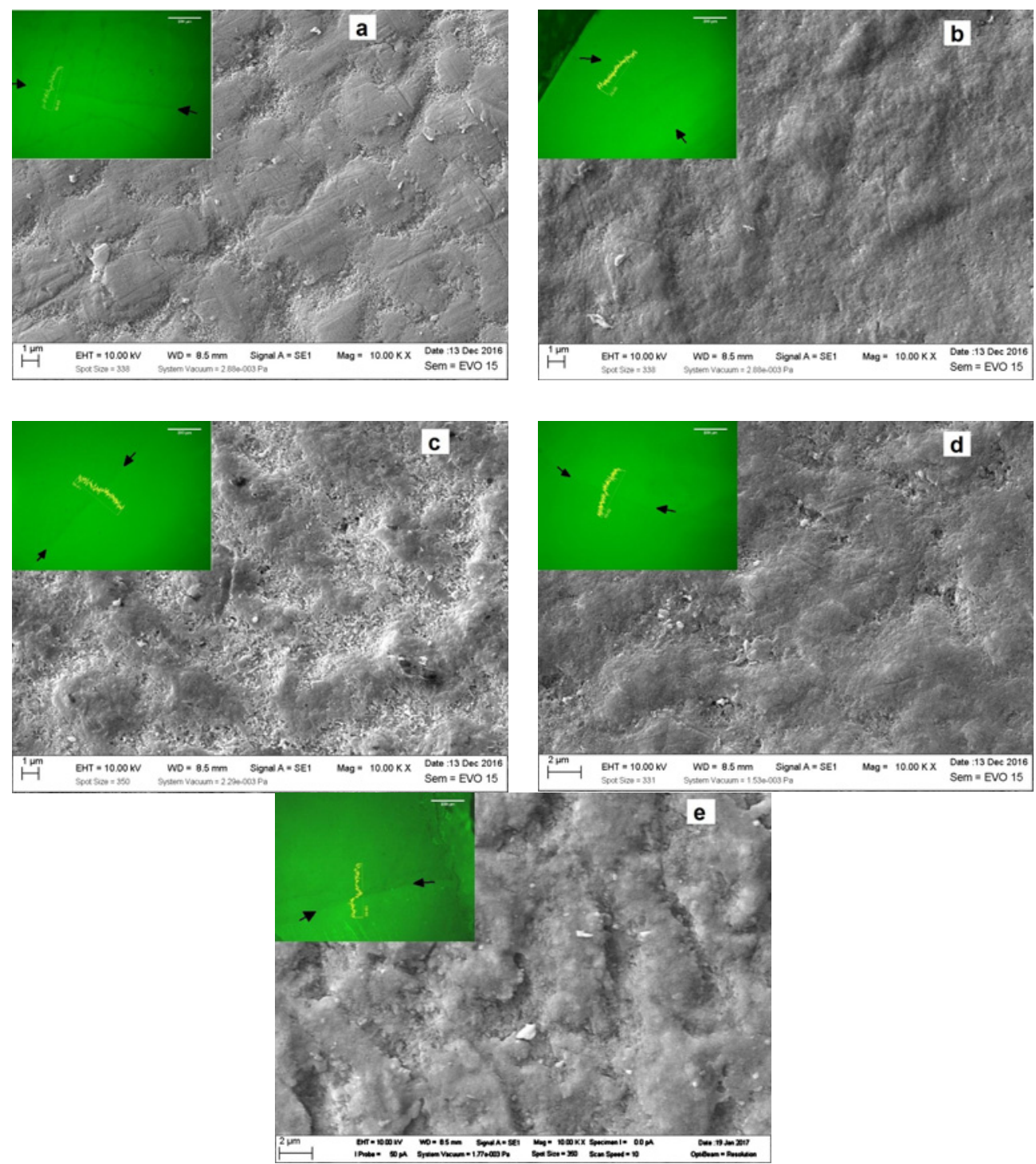

Fig.1. Surface microstructure of enamels after treatment and cycling with TTCPM (a), TTCPMF (b), micTTCPM (c), CaPSi (d) and control (storage solution; e). Fluorescent images from adjacent sound (S) and treated (T) enamels with fluorescent intensity line scan across boundary (arrows) in detail of micrographs.

The EDX analysis of TTCPM and TTPMF coatings verified about 7\% rise in the $\mathrm{Ca} / \mathrm{P}$ ratio while no change in ratio was found on CaPSi treated enamels (a low silica content (Fig.2b) was revealed in coating only). Besides the increase of magnesium content (about double) in all enamel surfaces as compared with sound enamels was confirmed after cycling (Fig.2c,d). 

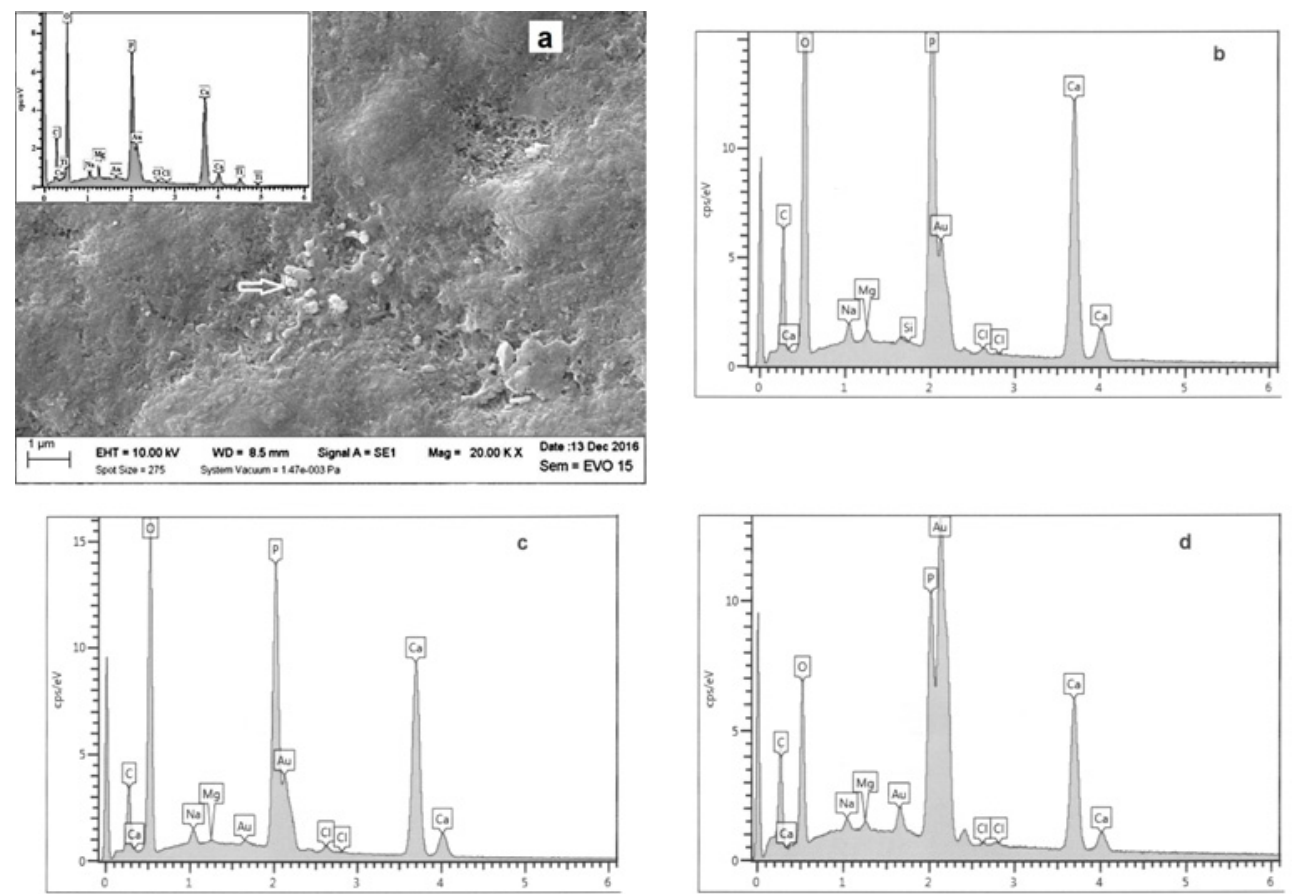

Fig.2. EDX semiquantitative analysis of CaPSi (a- SEM + point EDX analysis of microparticles, b- area EDX microanalysis after cycling) and TTCPMF groups (c - sound enamel, $d-$ after cycling, both analysis from area).

On cross-sections of fractured enamels at higher magnification, the formation of continuous coating composed of very fine precipitates can be visible after cycling (Fig.3a,b).The average coating thickness on enamels of TTCPMF group after soaking in storage solution was almost triple (around $150 \mathrm{~nm}$ ) than on untreated enamel (about $50 \mathrm{~nm}$ ).

In the case of $\Delta \mathrm{h}$, the statistically significant differences $(\mathrm{p}<0.05)$ were measured between control storage solution group and all paste groups irregardless the type of dentifrice whereas no differences were identified within toothpaste groups. Note that 30-50 $\%$ reduction of $\Delta \mathrm{h}$ in dentifrice groups was measured as compared to control.
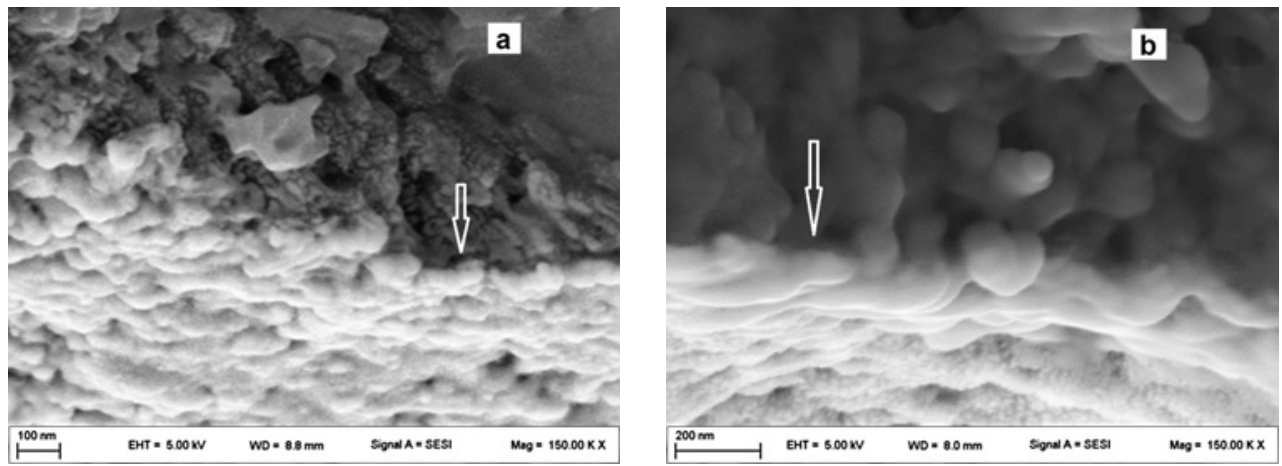

Fig.3. SEM micrographs from cross-sections of teeth with surface protective coating on enamels after cycling ( $\mathrm{a}$ - control storage solution group; $\mathrm{b}$ - TTCPMF group). 
About $18 \%$ reduction in VHM of TTCP treated enamels after cycling relatively to sound enamel resulted from evaluation of $\triangle \mathrm{VMH}$ but changes were significantly lower $(p<0.05)$ than in control group (storage solution only). No statistically significant differences in $\triangle \mathrm{VMH}$ were revealed within toothpaste TTCPMF and micTTCPM $(\mathrm{p}>0.62)$ or $\mathrm{CaSiP}(\mathrm{p}>0.35)$ groups contrary to TTCPM and TTCPMF or CaSiP groups, which were statistically different $(\mathrm{p}<0.05)$. Null hypothesis for $\triangle \mathrm{VMH}$ was accepted in the case of TTCPMF, micTTCPM and CaPSi groups, thus, enamels were almost fully remineralized after cycling. The analysis of the fluorescent intensity (Tab.1) of polished sound and treated enamel surfaces (details in Fig.1 show the fluorescent line scan intensities across the boundary between sound and treated enamel surfaces) clearly demonstrates very low differences between the fluorescent intensities and statistically insignificant differences within dentifrice groups what is in accordance with $\triangle \mathrm{VMH}$ measurements. On the other hand, around $45 \%$ reduction in $\Delta \mathrm{VMH}$, the decrease in intensity of fluorescence of etched enamel halves as well as more than $30 \%$ rise in $\Delta \mathrm{h}$ were identified in negative control group what shows only limited ability of storage solution to enamel remineralization or protection to acid attack. Note that no subsurface enamel lesions were observed by the fluorescent method (direct fluorescence of enamels or after diffusion of rhodamine B to enamel structures) on the cross sections of enamels after cycling.
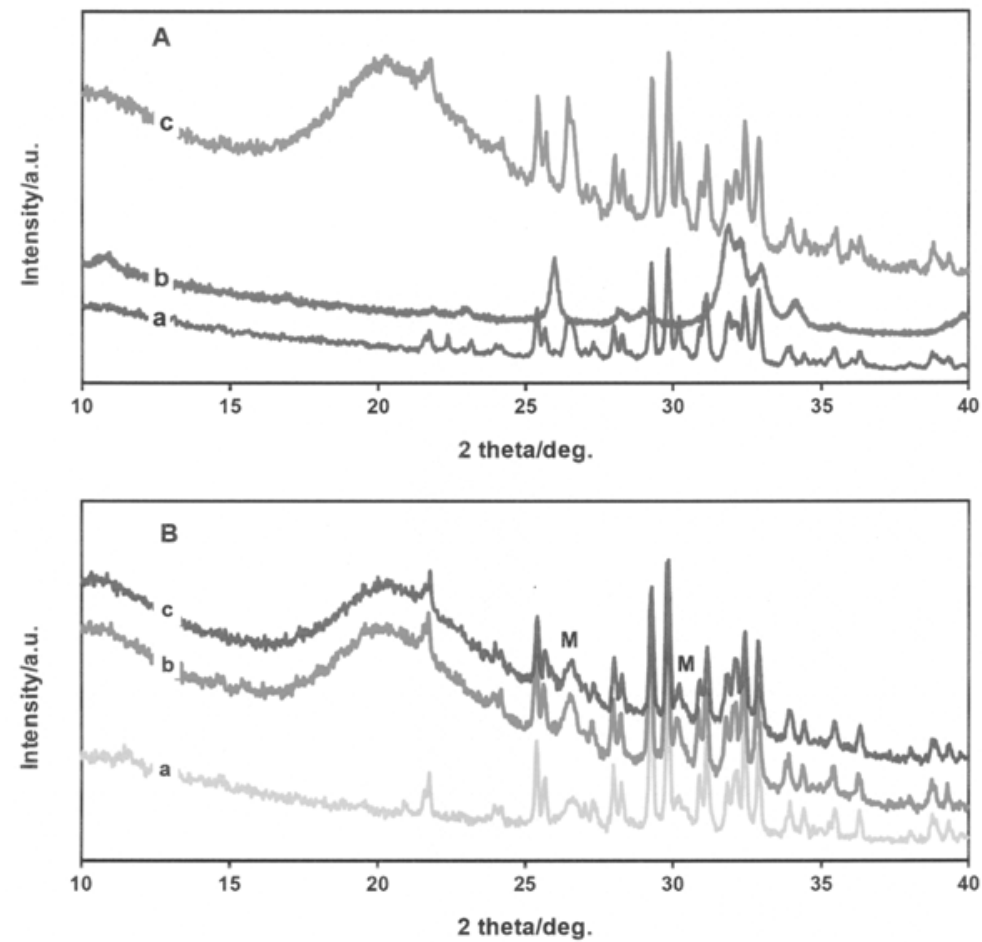

Fig.4. XRD patterns of micTTCPM (A) and TTCPM, TTCPMF (B) toothpastes after one year from preparation stored in closed PP vials $(\mathrm{A}: \mathrm{a}-$ micTTCPM powder mixture, $\mathrm{b}-$ nanohydroxyapatite, $\mathrm{c}-$ micTTCPM toothpaste; $\mathrm{B}$ : a- tetracalcium phosphate/nanomonetite powder mixture, $\mathrm{b}$ - TTCPM toothpaste, c- TTCPMF toothpaste; M-monetite). 
The chemical stability of tetracalcium phosphate/monetite mixture in toothpastes during one year storage is demonstrated in Fig.4. No additional lines from new phases like e.g. brushite or hydroxyapatite created by transformation of dentifrice components were found in XRD patterns after storage period. From comparison of XRD patterns of the micTTCPM powder component (Fig.4a) with TTCPMF mixture (Fig.4b) resulted a more crystalline character of monetite (JCPDS 09-0080) in micTTCPM because of the higher intensity of lines and visible splitting of narrowed lines from reflections of (002) and (-220) monetite planes at $2 \theta \sim 26.5^{\circ}$. The broad XRD line in patterns of toothpastes around $2 \theta \sim$ $20^{\circ}$ arises from nanocrystalline silica as one of toothpaste components.

\section{DISCUSSION}

The commercial TEETHMATE ${ }^{\circledR}$ desensitizer has been studied as dentin desensitizer and the effective tool in preventing demineralization of root dentin but application in the form of slurry showed the insufficient formation of precipitates and incomplete porous coverage of dentin surface [23]. The tetracalcium phosphate/monetite mixtures represent well known biocement self-setting basis developed for bone defect healing with the fast hydrolysis especially the tetracalcium phosphate in aqueous media (with the formation of calcium hydroxide) followed the acido-basic reaction with acid component (monetite) in mixture. The final product of their mutual interaction is the fine nanocrystalline calcium deficient hydroxyapatite $[24,30]$. The utilization of this mixture in dentifrices had several advantages e.g. the rapid rise in $\mathrm{pH}$ of surrounding, the increase in calcium and phosphate concentrations during brushing with possibility of the rapid nucleation or precipitation of hydroxyapatite on enamel. The rate of cement component transformation due to above described processes depends on physico-chemical properties of phases, appropriate $\mathrm{Ca} / \mathrm{P}$ ratio and the particle size distribution of powder calcium phosphates as well as on the presence of other chemically active ingredients in toothpastes. Note that the water content in TTCPM dentifrices is critical parameter for achievement of the long-term stability of calcium phosphates during storage in dentifrices and has to be optimized. On the other hand, it is appropriate to admix a small water amount to toothpaste for the partial gelation of some additives (CMC, carrageenan) and enhancing the solubility for example xylitol (or taste ingredients, preservatives, detergents etc.). As resulted from XRD analysis, no lines from nanocrystalline hydroxyapatite phase were identified in XRD patterns of dentifrices after one year storage. This fact verifies that the composition of dentifrices was proper in relation to their stability at used water content.

Fluorides are another anti-caries active components in dentifrices with generally accepted at concentration between $1100-1450 \mathrm{ppm} \mathrm{F}^{-}$and this amount was added to TTCPMF dentifrice as NaF. Note that $\mathrm{NaF}$ was re-precipitated before toothpaste preparation for reduction of the average particle size to submicron dimensions that enhancing the solubility and reactivity of fluorides in a short time after application of TTCPMF toothpaste with a more active calcium phosphate mixture. The surface roughness of enamel is interesting parameter not only for the aesthetic reasons but also for suppression of the bacterial adhesion and subsequent plaque formation in the oral environment. The significant smoothening of enamels treated with fluoride dentifrices was identified which demonstrates the effective influence of fluoride ions on the formation of protective coating despite the fact that no fluorine was found by EDX analysis in layers. Note that detection possibilities of EDX method to determine of low element contents (tenths of wt \%) are limited. Contrary to fluorine, the EDX analysis of coatings showed the rapid rise in magnesium content relative to sound enamels which confirms the precipitation of extremely fine calcium and magnesium phosphates (observed by SEM) originating from the storage 
solution. It is well known the ability of artificial or natural saliva to partial remineralization of enamel [29, 31, 32] in dependence on the actual supersaturation of saliva to hydroxyapatite according to surrounding conditions. The calcium phosphate based pastes like ACP, CPP-ACPF and especially fTCP had a strong effect on reduction of the surface roughness and improving the enamel acid-resistance [4, 33]. The 10\% content of nanohydroxyapatite represented the optimal amount of nanohydroxyapatite to direct filling up demineralized enamel in defects and micropores. These adhered particles act as a template on enamel for following precipitation process in remineralization solution and promote growth of hydroxyapatite particles [20,21]. Similar approximately $15 \mathrm{wt} \%$ content of the calcium phosphates was used in TTCPM dentifrices but their remineralization potential was significantly enhanced as compared with above works. The precipitation of hydroxyapatite in the form of fine deposits can be enhanced in the presence of fluoride ions because the fluoroapatite created by the substitution of fluoride ions for $\mathrm{OH}^{-}$in hydroxyapatite lattice has a lower solubility constant. Thus the higher degree of supersaturation can be achieved in saliva. These conditions conditions allow production of the higher number of nuclei or precipitates which are more uniformly distributed on enamel surface during a short time period after dentifrice application. It is clear that the precipitation of a new phase starts on enamel sites at which the chemical activity was enhanced by the chemical etching. The partial dissolution of hydroxyapatite in starting demineralization step opens the enamel structure with rise in active surface area to remineralization by any external sources of calcium and phosphates. The enhanced number of fine deposites due to faster release of highly active ions from the TTCPMF toothpaste during brushing was responsible for a more intense precipitation of calcium phosphate layer on enamels and reduction in the surface roughness of coatings. On the other hand, micTTCPM group showed better remineralization properties than TTCPM group. The coating in micTTCPM group had a higher porosity which demonstrates nonuniform heterogeneous precipitation of hydroxyapatite probably on particles of partially transformed components with the local supersaturation and faster growth due to larger difference between the surface Gibbs free energy of coarser and finer precipitates. The thicker but more porous layer are formed by this process.

No differences in $\Delta \mathrm{h}$ between toothpaste groups were found but the application of dentifrices significantly reduced $\Delta \mathrm{h}$ as compared with control solution group. This shows the direct effect of dentifrices on the formation of a more compact protection coatings in remineralization solution. The comparison of $\triangle \mathrm{VMH}$ revealed the lowest ability of the TTCPM group to enamel remineralization contrary to other dentifrices with fully remineralized enamel surfaces (null hypothesis) but the decrease in $\triangle \mathrm{VMH}$ of TTCPM group was much lower than in control (around 40\%). The fluorescent method allows to detect and longitudinally monitor the creation of artificial lesions on extracted human teeth relying upon the relationship between enamel fluorescencent intensity and mineralization statu $^{25}$. Direct observations of eroded enamels after cycling by the fluorescent optical microscopy demonstrated comparable results like VHM measurements. Thus, no statistically significant differences were identified within individual groups in $\Delta \mathrm{I}_{\text {fluor }}$. Despite of the small positive differences or decrease in $\mathrm{I}_{\text {fluor }}$ of treated enamels (null hypothesis were rejected), $\Delta \mathrm{I}_{\text {fluor }}$ were about 3-4 times lower than $\Delta \mathrm{I}_{\text {fluor }}$ of control group. This fact shows a much effective remineralization of enamels after treatment with any of used dentifrices. Above results are in accordance with other published works e.g. the stronger effect of $10 \%$ nanohydroxyapatite slurry in saliva on the enamel remineralization than $2 \% \mathrm{NaF}$ solution [34] or reduction in the microhardness loss of enamel even in mixture of slurry with acid hydrogen peroxide solution. 
In conclusion, the new dentifrice with the active tetracalcium phosphate/monetite mixture showed excellent enamel remineralization potential under de/remineralization cycling comparable with commercial calcium silicate/phosphate toothpastes. It was demonstrated that all toothpaste groups much effectively reduced enamel losses and surface roughness with the fully surface microhardness recovery than control solution group and null hypothesis could be rejected. The addition of fluorides in amount of $1450 \mathrm{ppm}$ to TTCPM significantly improved remineralization activity of toothpaste with nanomonetite phase. The results verified long-term stability of prepared dentifrices which could be used in household as current toothpastes.

\section{Acknowledgement}

This work was supported by the Slovak Grant Agency of the Ministry of Education of the Slovak Republic and the Slovak Academy of Sciences, Project No. 2/0047/17.

\section{REFERENCES}

[1] Li, X., Wang, J., Joiner, A., Chang, J.: J. Dent., vol. 42, 2014, p. 12

[2] Da Camara, DM., Pessan, JP., Francati, TM., Santos Souza, JA., Danelon, M., Delbem, AC.:. J. Dent., vol. 43, 2015, p. 1249

[3] Danelon, M., Pessan, JP., Neto, FNS., De Camargo, ER., Delbem, AC.: J. Dent., vol. 43, 2015, p. 806

[4] Shen, P., Manton, DJ., Cochrane, NJ., Walker, GD., Yuan, Y., Reynolds, C., Reynolds, EC.: J. Dent., vol. 39, 2011, p. 518

[5] Li, J., Xie, X., Wang, Y., Yin, W., Antoun, JS., Farella, M., Mei, L.: J. Dent., vol. 42, 2014, p. 769

[6] Cochrane, NJ., Cai, F., Huq, NL., Burrow, MF., Reynolds, EC.: J. Dent. Res., vol. 89, 2010, 1187

[7] Wang, Y., Li, X., Chang, J., Wu, C., Deng, Y.: J. Dent., vol. 40, 2012, p. 1119

[8] Nidhi, G., Kunwarjeet, S.: J. Pharm. Biomed. Sci., vol. 24, 2012, p. 79

[9] Hannig, M., Hannig, C.: Adv. Dent. Res., vol. 24, 2012, p. 53

[10] Hornby, K., Ricketts, SR., Philpotts, CJ., Joiner, A., Schemehorn, B., Willson, R.: J. Dent., vol.42, 2014, p. 39

[11] Jones, SB., Davies, M., Chapman, N., Willson, R., Hornby, K., Joiner, A., West, NX.: J. Dent., vol. 42, 2014, p. 46

[12] Joiner, A., Schäfer, F., Naeeni, MM., Gupta, AK., Zero, DT.: J. Dent., vol. 42, 2014, p. 53

[13] Sun, Y., Li, X., Deng, Y., Sun, JN., Tao, D., Chen, H., Hu, Q., Liu, R., Liu, W., Feng, X., Wang, J., Carvell, M., Joiner, A.: J. Dent., vol. 42, 2014, p. 30

[14] Zaze, AC., Dias, AP., Amaral, JG., Miyasaki, ML., Sassaki, KT., Delbem, AC.: J. Dent., vol. 42, 2014, p. 1621

[15] De Alencar, CRB., Magalhaes, AC., De Andrade Moreir Machado, MA., De Oliviera, TM., Honorio, HM., Rios, D.: J. Dent., vol. 42, 2014, p. 1502

[16] Mathews, MS., Amaechi, BT., Ramalingam, K., Ccahuana-Vasquez, RA., Chedjieu, IP., Mackey, AC., Karlinsey, RL.: Arch. Oral. Biol., vol. 57, 2012, p. 525

[17] Vanichvatana, S., Auichay, P.: Inter. J. Oral. Sci., vol. 5, 2013, p. 224

[18] Tschoppe, P., Zandim, DL., Martus, P., Kielbassa, AM.: J. Dent., vol. 39, 2011, p. 430

[19] Esteves-Oliveira, M., Santos, NM., Meyer-Lueckel, H., Wierichs, RJ., Rodrigues, JA.: Clin. Oral. Invest., vol. 24, 2017, p. 291

[20] Jiang, T., Ma, X., Wang, Z., Tong, H., Hu, J., Wang, Y.: J. Dent., vol. 36, 2008, p. 907 
[21] Huang, SB., Gao, SS., Yu, HY.: Biomed. Mater., vol. 4, 2009, p. 034104

[22] Min, JH., Kwon, HK., Kim, BI.: J. Dent., vol. 39, 2011, p. 629

[23] Lodha, E., Hamba, H., Nakashima, S., Sadr, A., Nikaido, T., Tagami, J.: Eur. J. Oral. Sci., vol. 122, 2014, p. 404

[24] Medvecky, L., Giretova, M., Stulajterova, R., Kasiarova, M.: Biomed. Mater., vol.10, 2015, p. 025006

[25] Pretty, IA., Pender, N., Edgar, WM., Higham, SM.: Eur. J. Orthod., vol. 25, 2003, p. 217

[26] Pretty, IA., Hall, AF., Smith, PW., Edgar, WM., Higham, SM.: Br. Dent. J., vol. 193, 2002, p. 105

[27] Shellis, RP., Ganss, C., Ren, Y., Zero, DT., Lussi, A.: Caries. Res., vol. 45, 2011, p. 69

[28] Niu, LN., Zhang, W., Pashley, DH., Breschi, L., Mao, J., Chen, JH., Tay, FR.: Dent. Mater., vol. 30, 2014, p. 77

[29] Ionta, FQ., Mendonca, FL., De Oliveira, GC., De Alencar, CRB., Honorio, HM., Magalhaes, AC., Rios, D.: J. Dent., vol. 42, 2014, p. 175

[30] Hirayama, S., Takagi, S., Markovic, M., Chow, LC.: J. Res. Natl. Ins.t Stand Technology, vol. 113, 2008, p. 311

[31] Amaechi, BT., Higham, SM.: J. Dent., vol. 29, 2001, p. 371

[32] Larsen, MJ., Pearce, EIF.: Arch. Oral. Biol., vol. 48, 2003, p. 317

[33] Elkassas, D., Arafa, A.: J. Dent., vol. 42, 2014, p. 466

[34] Swarup, JS., Rao, A.: Contemp. Clin. Dent., vol. 3, 2012, p. 433 